\title{
A Comprehensive Evaluation of Early Predictors of Disease Progression in Patients with COVID-19: A Case Control Study
}

\author{
Qiang Tang \\ Taihe Hospital \\ Yanwei Liu \\ Taihe Hospital \\ Yingfeng Fu \\ Taihe Hospital \\ Ziyang Di \\ Taihe Hospital \\ Kailiang Xu \\ Jinzhou Medical University \\ Bo Tang \\ Taihe Hospital \\ Hui Wu \\ Taihe Hospital \\ Maojun Di ( $\triangle$ maojunndi@163.com ) \\ Taihe Hospital
}

\section{Research Article}

Keywords: Coronavirus, COVID-19, disease progression, predictors, treatment

Posted Date: August 3rd, 2020

DOI: https://doi.org/10.21203/rs.3.rs-50527/v1

License: (1) (1) This work is licensed under a Creative Commons Attribution 4.0 International License. Read Full License 


\section{Abstract}

Background: The 2019 coronavirus disease (COVID-19) has become an unprecedented public health crisis with nearly 16 million confirmed cases and 630,000 deaths worldwide.

Methods: We retrospectively investigated the demographic, clinical, laboratory, radiological and treatment data of COVID-19 patients consecutively enrolled from January 18 to May 15, 2020, in Taihe and Jinzhou central hospital.

Results: Of all 197 patients, the median age was 66.5 years (IQR 7-76), and 120 (60.9\%) patients were males. We identified 88 (44.7\%) of 197 COVID-19 patients as the disease progression (aggravation) cases. The aggravation cases tend to have more medical comorbidity: hypertension (34.1\%), diabetes (30.7\%), and presented with dyspnea (34.1\%), neutrophilia (60.2\%), and lymphocytopenia (73.9\%), compared with those without. And the patients with disease progression showed significantly higher level of Fibrinogen (Fbg), D-dimer, IL-6, C-reactive protein (CRP), procalcitonin (PCT), and serum ferritin, and were more prone to develop organ damage in the liver, kidney, and heart $(P<0.05)$. Multivariable regression showed that advanced age, comorbidities, lymphopenia, and elevated level of Fbg, lactate dehydrogenase (LDH), Cardiac troponin (CTnI), IL-6, serum ferritin were the significant predictors of disease progression. Further, we investigated antibody responses to SARS-CoV-2 and found that the levels of $\operatorname{lgM}$ and IgG were significantly higher in the disease progression cases compared to nonprogression cases from 3 weeks after symptom onset. In addition, the disease progression group tended to peak later and has a more vigorous IgM/lgG response against SARS-CoV-2. Further, we performed Kaplan-Meier analysis and found that $61.6 \%$ of patients had not experienced ICU transfer or survival from hospital within 25 days from admission.

Conclusions: Investigating the potential factors of advanced age, comorbidities and elevated level of IL-6, serum ferritin and Kaplan-Meier analysis enables early identification and management of patients with poor prognosis. Detection of the dynamic antibody may offer vital clinical information during the course of SARS-CoV-2 and provide prognostic value for patients infection.

\section{Introduction}

In December 2019, the outbreak of unidentified pneumonia has aroused great attention all over the world, which is not only an epidemic but even a disaster (1). On January 27 of 2020, the World Health Organization (WHO) issued worldwide surveillance and vigilance of the highly contagious respiratory diseases and formulated the first edition of prevention and control strategies (2). Sequence analysis of the coronavirus from lower respiratory tract samples has shown a structure typical to that of other coronaviruses such as SARS coronavirus and MERS coronavirus $(3,4)$. And then the WHO named the unidentified Coronavirus as SARS-CoV-2 and the pneumonia of unknown origin as COVID-19 $(5,6)$. SARSCoV-2 belongs to a unique clade of the sarbecovirus subgenus of the Orthocoronavirinae subfamily $(7,8)$. 
Evidence has been found that SARS-CoV-2 is extremely contagious to humans, and could be transmitted through respiratory droplets, contact, and even via fecal-oral transmission (9).

The clinical spectrum of SARS-CoV-2 pneumonia ranges from mild to critically ill cases. As reported in the literature, patients with COVID-19 mainly presented with fever, cough, fatigue, myalgia, dyspnea (10). Most patients represented various degrees of abnormality on imaging, and the moderate and severe phenotypes were always associated with pronounced imaging abnormalities $(9,11)$. Several studies have shown that the majority of patients were considered to have a favorable prognosis, however, elderly men and those with underlying diseases including hypertension, diabetes, chronic obstructive pulmonary disease (COPD), had a higher risk of developing acute respiratory distress syndrome (ARDS), which may be the leading cause of death $(12,13)$. Therefore, investigate the risk factors associated with disease progression are therefore greatly warranted. In this study, we investigated the clinical characteristics and relevant factors associated with the outcomes of patients with SARS-CoV-2 infection, which may provide considerable value for the early identification of individuals who are at risk of disease progression and who are most likely to benefit from intensive care treatment. We believe our findings will give further details to the epidemic situation and clinical characteristics of this novel coronavirus.

\section{Materials And Methods}

\section{Study participants and design}

This study was conducted in accordance with the Declaration of Helsinki and was approved by the Institutional Review Board of Taihe and Jinzhou central hospital, and all participants provided written informed consent before data were collected retrospectively. All of the patients were consecutively enrolled from January 18 to May 15, 2020, in Taihe and Jinzhou central hospital, who had been confirmed with COVID-19 infection according to World Health Organization interim guidance.

\section{Data collection}

We reviewed the clinical medical records of all patients to collect the demographic data and clinical and laboratory findings of the patients. All data including age, sex, occupation, symptoms (fever, fatigue, dry cough, myalgia, dyspnea, etc.), underlying comorbidities (COPD, cancer, hypertension, and diabetes), laboratory results (complete blood cell counts, creatinine, liver function tests, and inflammatory markers), treatment, and the outcomes data were retrospectively extracted with standardized data collection forms. If the variable were not available from electronic medical records or needed further clarification, we would clarify the details with the attending doctors and other health care providers. Clinical outcomes were followed up to Mar 15, 2020.

To identify the confirmed case, nasal and pharyngeal swab samples were obtained from patients at admission and were tested using the real-time reverse transcriptase polymerase-chain-reaction (RT-PCR). The exact date of onset was defined as the day when the symptom was noticed. A weekly assessment of disease progression was performed that provided details about the patients' clinical status. All study 
participants were divided into the disease progression group and non-progression group based on the specific criteria: (1). Progression group (aggravation): a higher body temperature than before, aggravated symptoms, and varied progression of imaging examination manifestation; (2). Non-progression group (non-aggravation): body temperature decreasing, symptom and imaging improvement, or no significant change in body temperature, respiratory symptoms, and imaging manifestation. ARDS and shock were defined according to the interim guidance of WHO for the novel coronavirus. Acute kidney injury was identified and classified based on the highest serum creatinine level or urine output criteria according to the kidney disease improving global outcomes classification. The cardiac injury was diagnosed if serum levels of cardiac biomarkers (e.g. Troponin I) were above the 99th percentile upper reference limit, or new abnormalities were shown in electrocardiography and echocardiography. Finally, a total of 197 subjects were enrolled in the study and divided into two groups: 88 cases with disease progression and 109 cases without disease progression.

\section{Statistical analysis}

Categorical variables were expressed as frequencies and numbers (\%) and analyzed using the Chisquared test or Fisher's exact test. The continuous variables were presented as median or interquartile ranges (IQR) values and Two-sided unpaired t-test or Mann-Whitney test was used as appropriate to compare groups. All statistical analyses and graphs were generated and plotted using GraphPad Prism (version 7.0) and SPSS (Statistical Package for the Social Sciences version 21.0). A confidence level of $p$ $<0.05$ was considered statistically significant for all analyses.

\section{Results}

\section{Demographic characteristics}

In this study, a total of 197 patients with COVID-19 were confirmed from Taihe Hospital and Jinzhou central hospital. The demographic and clinical characteristics are shown in Table 1. The median age of the patients was 66.5 years (IQR 7-76), and 97 (49.2\%) patients were older than 60 years. $120(60.9 \%)$ patients were males. And less than $20 \%$ of patients had a smoking history. Of the 197 patients, 72 (36.5\%) had at least one underlying chronic diseases, including hypertension (25.9\%), diabetes (20.8\%), COPD (18.8\%), cardiovascular disease (10.2\%), cerebrovascular diseases $(9.1 \%)$, malignancy $(8.1 \%)$, chronic kidney disease (7.6\%), chronic liver disease (10.2\%), HIV infection (4.6\%). Further, COVID-19 patients with ACEI/ARB therapy were enrolled, and we found that about $50.7 \%$ of patients had taken ACEI/ARB in the progression group, which is much higher than that of the control group (25\%). In addition, of these patients, 36 (18.3\%) were infected medical staff. 
Table 1

Clinical characteristics of the two groups

\begin{tabular}{|c|c|c|c|c|}
\hline $\begin{array}{l}\text { Clinical } \\
\text { characteristics }\end{array}$ & $\begin{array}{l}\text { Total patients }(n= \\
\text { 197) }\end{array}$ & $\begin{array}{l}\text { Non-aggravation }(\mathrm{n}= \\
109)\end{array}$ & $\begin{array}{l}\text { Aggravation } \\
(n=88)\end{array}$ & $\underset{v a l u e}{p}$ \\
\hline Age (year, IQR) & $66.5(7-76)$ & $60(47.5-67)$ & $53(32-64)$ & $<.001$ \\
\hline Male (n/\%) & $120(60.9 \%)$ & $59(54.1 \%)$ & $61(69.3 \%)$ & <. 001 \\
\hline Medical workers (n/\%) & $36(18.3 \%)$ & $33(30.3 \%)$ & $3(3.40 \%)$ & $<.001$ \\
\hline Smoking history (n/\%) & $31(15.74 \%)$ & $14(12.84 \%)$ & $17(19.32 \%)$ & 0.473 \\
\hline \multicolumn{5}{|l|}{ Comorbidity (n/\%) } \\
\hline Hypertension & $51(25.9 \%)$ & $21(19.3 \%)$ & $30(34.1 \%)$ & 0.018 \\
\hline Diabetes & $41(20.8 \%)$ & $14(12.8 \%)$ & $27(30.7 \%)$ & 0.002 \\
\hline ACEI or ARB $(n=92)$ & $38 / 92(41.3 \%)$ & $9 / 35(25.7 \%)$ & $29 / 57(50.7 \%)$ & 0.003 \\
\hline COPD & 37 (18.8\%) & $13(11.9 \%)$ & $24(27.3 \%)$ & 0.006 \\
\hline Cardiovascular disease & $22(11.2 \%)$ & $9(8.3 \%)$ & $13(14.8 \%)$ & 0.149 \\
\hline $\begin{array}{l}\text { Cerebrovascular } \\
\text { disease }\end{array}$ & $18(9.1 \%)$ & $7(6.4 \%)$ & $11(12.5 \%)$ & 0.141 \\
\hline Cancer & $16(8.1 \%)$ & $10(9.2 \%)$ & $6(6.8 \%)$ & 0.547 \\
\hline Chronic liver disease & $20(10.2 \%)$ & $9(8.3 \%)$ & $11(12.5 \%)$ & 0.626 \\
\hline Chronic kidney disease & $15(7.6 \%)$ & $9(8.3 \%)$ & $6(6.8 \%)$ & 0.705 \\
\hline HIV infection & $9(4.6 \%)$ & $4(3.7 \%)$ & $5(5.7 \%)$ & 0.501 \\
\hline \multicolumn{5}{|c|}{ Signs and symptoms at admission ( $\mathrm{n} / \%)$} \\
\hline Fever & $159(80.7 \%)$ & $89(81.7 \%)$ & $70(79.5 \%)$ & 0.82 \\
\hline Dry cough & $157(79.7 \%)$ & $88(80.7 \%)$ & $69(78.4 \%)$ & 0.687 \\
\hline Productive cough & $40(20.3 \%)$ & $18(16.5 \%)$ & $22(25.0 \%)$ & 0.16 \\
\hline Nasal congestion & $15(7.6 \%)$ & $10(9.2 \%)$ & $5(5.7 \%)$ & 0.358 \\
\hline Rhinorrhea & $9(4.6 \%)$ & $6(5.5 \%)$ & $3(3.4 \%)$ & 0.484 \\
\hline Myalgia or arthralgia & $45(22.8 \%)$ & $21(19.3 \%)$ & $24(27.3 \%)$ & 0.805 \\
\hline
\end{tabular}

Data are median (IQR), n (\%). 


\begin{tabular}{|c|c|c|c|c|}
\hline $\begin{array}{l}\text { Clinical } \\
\text { characteristics }\end{array}$ & $\begin{array}{l}\text { Total patients }(n= \\
\text { 197) }\end{array}$ & $\begin{array}{l}\text { Non-aggravation }(\mathrm{n}= \\
109)\end{array}$ & $\begin{array}{l}\text { Aggravation } \\
(n=88)\end{array}$ & $\underset{\text { value }}{p}$ \\
\hline $\begin{array}{l}\text { Headache and } \\
\text { dizziness }\end{array}$ & $29(14.7 \%)$ & $16(14.7 \%)$ & $13(14.8 \%$ & 0.985 \\
\hline Runny nose & $9(4.6 \%)$ & $6(5.5 \%)$ & $3(3.4 \%)$ & 0.484 \\
\hline Fatigue & $125(63.5 \%)$ & $63(57.8 \%)$ & $62(70.5 \%)$ & 0.067 \\
\hline Chest distress & $76(38.6 \%)$ & $34(31.2 \%)$ & $42(47.7 \%)$ & 0.018 \\
\hline Chest pain & $15(7.6 \%)$ & $6(5.5 \%)$ & $9(10.2 \%)$ & 0.214 \\
\hline Chills & $23(11.7 \%)$ & $10(9.2 \%)$ & $13(14.8 \%)$ & 0.224 \\
\hline Sneeze & $8(4.1 \%)$ & $5(4.6 \%)$ & $3(3.4 \%)$ & 0.677 \\
\hline Dyspnea & $46(23.4 \%)$ & $16(14.7 \%)$ & $30(34.1 \%)$ & 0.001 \\
\hline Abdominal pain & $19(9.6 \%)$ & $9(8.3 \%)$ & $10(11.4 \%)$ & 0.463 \\
\hline Nausea or vomiting & $22(11.2 \%)$ & $12(11 . \%$ & $10(11.4 \%$ & 0.937 \\
\hline Conjunctival hyperemia & $11(5.6 \%)$ & $5(4.6 \%)$ & $6(6.8 \%)$ & 0.498 \\
\hline $\begin{array}{l}\text { Oxygen partial } \\
\text { pressure(\%) }\end{array}$ & $94(87-97)$ & $97(94-99)$ & $88(80-93)$ & $\dot{0} 001$ \\
\hline $\begin{array}{l}\text { Onset of symptom } \\
\text { to hospital admission }\end{array}$ & $5(3-8)$ & $5(3-9)$ & $5(3-7)$ & 0.4 \\
\hline \multicolumn{5}{|c|}{ Data are median (IQR), n (\%). } \\
\hline
\end{tabular}

Signs and symptoms of the patients on admission are shown in Table 1. The most common symptoms at the onset of illness were fever (81.5\%), dry cough (79.7\%), followed by fatigue (63.5\%), chest distress (38.6\%), dyspnea (23.4\%). The majority of patients (76.6\%) had both fever and cough. $89(45.3 \%)$ had a fever with fatigue, and $72(36.8 \%)$ patients had a fever with dyspnea; The less common symptoms were rhinorrhea (4.6\%), runny nose (7.6\%), and chest pain (7.6\%). Notably, we found that $24(12.7 \%)$ patients represented at least one gastrointestinal symptom including abdominal pain (9.6\%) nausea or vomiting (11.2\%). Besides, 11 (5.6\%) patients were clinically characterized by conjunctival hyperemia. Though, these digestive and ocular symptoms were less common in COVID-19 patients, special attention should be paid to the care of this unique group of patients. The median time from onset to hospital admission was 5.0 days $(3.0-8.0)$.

\section{Laboratory findings}

The laboratory findings of the confirmed patients are summarized in Table 2. Of 197 patients, 62 (31.5\%) cases showed an increased presence of neutrophils, and $92(46.7 \%)$ cases had lymphocytopenia. Severe 
patients showed liver injury with elevated level of aspartate aminotransferase (AST, 34\%), alanine aminotransferase (ALT, 36.5\%), total bilirubin (TBIL, 7.6\%), direct bilirubin (DBIL, 12.2\%), Albumin (17.3\%). Approximately one-quarter of patients exhibited myocardial injury with elevated lactate dehydrogenase (LDH, 52.4\%), myoglobin (MYO, 27.1\%), Cardiac Troponin I (CTnl, 35.6\%), N-terminal-pro-B-type natriuretic peptide (ProBNP, 23.5\%). Some patients exhibited kidney injury indicated by elevated plasma urea $(30.5 \%)$ and serum creatinine (10.2\%). Some patients showed increased high sensitivity C-reactive protein (CRP, 54.4\%) and procalcitonin (PCT, 32.6\%). In addition, some patients showed coagulation dysfunction with elevated prothrombin time (PT, 17.9\%), activated partial thromboplastin time (APTT, 24.1\%), D-dimer (27.2\%), fibrinogen (Fbg, 21.3\%). 
Table 2

Initial Laboratory Indices of Patients with COVID-19.

\begin{tabular}{|c|c|c|c|c|}
\hline Variables & $\begin{array}{l}\text { Normal } \\
\text { range }\end{array}$ & $\begin{array}{l}\text { No. of } \\
\text { patients }\end{array}$ & Median (IQR) & $\begin{array}{l}\text { No. of patients with value } \\
\text { deviation (\%) }\end{array}$ \\
\hline \multicolumn{5}{|l|}{$\begin{array}{l}\text { Hematologic } \\
\star 10^{9} / \mathrm{L}\end{array}$} \\
\hline White blood cells & $3.5-9.5$ & 197 & $\begin{array}{l}5.78(4.56- \\
9.13)\end{array}$ & $68(34.5 \%)^{a}$ \\
\hline Neutrophils & $1.8-6.3$ & 197 & $\begin{array}{l}3.94(2.48- \\
8.14)\end{array}$ & $62(31.5 \%)^{a}$ \\
\hline Lymphocytes & $1.1-3.2$ & 197 & $\begin{array}{l}1.17(0.71- \\
1.78)\end{array}$ & $92(46.7 \%)^{\mathrm{b}}$ \\
\hline Platelets & $125-350$ & 197 & $197(156-266)$ & $37(18.8 \%)^{b}$ \\
\hline CD3 & $723-2737$ & 162 & $\begin{array}{l}812(395- \\
1128)\end{array}$ & $77(47.5 \%)^{b}$ \\
\hline $\mathrm{CD} 4$ & $404-1612$ & 177 & $427(190-615)$ & $83(46.9 \%)^{b}$ \\
\hline CD8 & $220-1129$ & 173 & $291(151-460)$ & $66(38.2 \%)^{b}$ \\
\hline CD16 + CD 56 & $80-610$ & 153 & $154(117-251)$ & $23(19 \%)^{b}$ \\
\hline CD19 & $84-724$ & 167 & $154(105-254)$ & $66(39.5 \%)^{b}$ \\
\hline \multicolumn{5}{|l|}{ Biochemical } \\
\hline AST, U/L & $15-40$ & 197 & $24(16-38)$ & $67(34 \%)^{a}$ \\
\hline$A L T, U / L$ & $9-50$ & 197 & $27(18-55)$ & $72(36.5 \%)^{a}$ \\
\hline ALP, U/L & $10-60$ & 197 & $58(48.4-79)$ & $68(34.5 \%)^{a}$ \\
\hline $\begin{array}{l}\text { Total bilirubin, } \\
\mu \mathrm{mol} / \mathrm{L}\end{array}$ & $0-23$ & 197 & $8.9(6.8-11.65)$ & $15(7.6 \%)^{a}$ \\
\hline $\begin{array}{l}\text { Direct bilirubin } \\
\mu \mathrm{mol} / \mathrm{L}\end{array}$ & $0-8$ & 197 & $4.6(4-7.4)$ & $24(12.2 \%)^{a}$ \\
\hline Albumin, g/L & $40.0-55.0$ & 197 & $37(32.9-39.5)$ & $34(17.3 \%)^{a}$ \\
\hline PCT, mg/L & $<0.05$ & 184 & $\begin{array}{l}0.09(0.04- \\
1.44)\end{array}$ & $60(32.6 \%)^{a}$ \\
\hline $\mathrm{BUN}, \mathrm{mmol} / \mathrm{L}$ & $3.1-8$ & 197 & $\begin{array}{l}4.63(3.95- \\
7.35)\end{array}$ & $60(30.5 \%)^{a}$ \\
\hline
\end{tabular}

${ }^{a}$ Above reference. ${ }^{b}$ Below reference. Data are median (IQR), n (\%). 


\begin{tabular}{|c|c|c|c|c|}
\hline Variables & $\begin{array}{l}\text { Normal } \\
\text { range }\end{array}$ & $\begin{array}{l}\text { No. of } \\
\text { patients }\end{array}$ & Median (IQR) & $\begin{array}{l}\text { No. of patients with value } \\
\text { deviation (\%) }\end{array}$ \\
\hline Creatinine, $\mu \mathrm{mol} / \mathrm{L}$ & $57-97$ & 197 & $55(49-99)$ & $20(10.2 \%)^{a}$ \\
\hline $\begin{array}{l}\text { Creatinine kinase, } \\
\mu \mathrm{M}\end{array}$ & $<171$ & 178 & $62(40-114.75)$ & $17(9.6 \%)^{a}$ \\
\hline CK-MB, U/L & $<25$ & 176 & $1.7(1-5.21)$ & $48(27.3 \%)^{a}$ \\
\hline MYO, $\mu \mathrm{g} / \mathrm{L}$ & $0-100$ & 192 & $\begin{array}{l}56.6(33.8- \\
113)\end{array}$ & $52(27.1 \%)^{a}$ \\
\hline $\mathrm{CTnl}, \mathrm{ng} / \mathrm{mL}$ & $0-0.04$ & 146 & $\begin{array}{l}0.016(0.006- \\
0.08)\end{array}$ & $52(35.6 \%)^{a}$ \\
\hline ProBNP & & 149 & $\begin{array}{l}106.5(38.1- \\
551)\end{array}$ & $35(23.5 \%)^{a}$ \\
\hline $\mathrm{LDH}, \mathrm{U} / \mathrm{L}$ & $125-243$ & 189 & $246(172-375)$ & $99(52.4 \%)^{a}$ \\
\hline $\begin{array}{l}\text { Potassium, } \\
\mathrm{mmol} / \mathrm{L}\end{array}$ & $3.5-5.5$ & 191 & $140(138-142)$ & $91(47.6 \%)^{a}$ \\
\hline Sodium, $\mathrm{mmol} / \mathrm{L}$ & $135-145$ & 191 & $3.89(3.6-4.37)$ & $51(26.7 \%)^{a}$ \\
\hline PT, s & $9.4-12.5$ & 195 & $\begin{array}{l}11.8(11.1- \\
12.5)\end{array}$ & $35(17.9 \%)^{a}$ \\
\hline APTT, s & $25.1-36.5$ & 190 & $28.9(26.3-31)$ & $28(24.1 \%)^{a}$ \\
\hline D-dimer, mg/mL & $0-0.55$ & 195 & $0.8(0.3-6.12)$ & $53(27.2 \%)^{a}$ \\
\hline Fbg, g/L & $2-4$ & 183 & $\begin{array}{l}3.33(2.68- \\
4.83)\end{array}$ & $39(21.3 \%)^{a}$ \\
\hline \multicolumn{5}{|c|}{ Inflammation immunologic related indices } \\
\hline $\mathrm{CRP}, \mathrm{mg} / \mathrm{L}$ & $0-10$ & 169 & $14.1(5-73)$ & $92(54.4 \%)^{a}$ \\
\hline $\begin{array}{l}\text { Serum ferritin, } \\
\mathrm{ng} / \mathrm{mL}\end{array}$ & $<300$ & 197 & $276(230-445)$ & $67(34.0 \%)^{a}$ \\
\hline $\begin{array}{l}\text { Procalcitonin, } \\
\mathrm{ng} / \mathrm{mL}\end{array}$ & $<0.1$ & 174 & $\begin{array}{l}0.34(0.06- \\
1.49)\end{array}$ & $60(32.6 \%)^{a}$ \\
\hline IL-6, pg/L & $\leq 20$ & 197 & $18.6(14.5-27)$ & $71(36.6 \%)^{a}$ \\
\hline IL-10, pg/L & $\leq 5.9$ & 197 & $5.58(4.2-10.2)$ & $76(38.6 \%)^{a}$ \\
\hline TNF, pg/L & $\leq 5.5$ & 197 & $4.8(4.2-6.6)$ & $62(31.5 \%)^{a}$ \\
\hline
\end{tabular}


There existed many differences in laboratory parameters between patients with disease progression and non-progression patients in Table 3. In the aggravation group, the total lymphocyte was significantly decreased in comparison with the non-aggravation group $(P=0.001)$. The cell count of the lymphocyte subtype was then further analyzed, which revealed that the count of $\mathrm{CD}^{+}, \mathrm{CD}^{+}$and $\mathrm{CD} 8^{+} \mathrm{T}$ cell in aggravation group was significantly lower than that of the non-aggravation group $(P<0.05)$, but there was no difference in the counts of $\mathrm{CD}^{+} 6^{+}$and $\mathrm{CD} 19^{+}$cells $(P>0.05)$. We also found that the number of neutrophils was notably increased in the patients of aggravation group $(P<0.001)$. Blood biochemical examination results suggested that patients with disease progression demonstrated higher levels of AST, Albumin, BUN, Creatinine, CK-MB, CTnl, ProBNP, LDH. At present, some researchers reported that the coagulation function would be dysregulation with the aggravation of the disease. We concluded that the levels of D-dimer, and Fbg were remarkably elevated in the aggravation patients. Table 3. also revealed the differences in inflammation immunologic related indices between the two groups. It suggested that the level of CRP, serum ferritin, procalcitonin, and IL- 6 were significantly higher in the aggravation group. 
Table 3

Laboratory findings of patients infected with COVID-19.

\begin{tabular}{|c|c|c|c|}
\hline Variables & $\begin{array}{l}\text { Non-aggravation } \\
(n=109)\end{array}$ & $\begin{array}{l}\text { Aggravation } \\
(n=88)\end{array}$ & $p$ value \\
\hline \multicolumn{4}{|l|}{ Hematologic $* 10^{9} / \mathrm{L}$} \\
\hline White blood cells & $5.47(3.56-7.18)$ & $6.8(4.44-13.13)$ & 0.06 \\
\hline Neutrophils & $2.81(2.31-4.06)$ & 7.75 (4.32-11.77) & $<0.001$ \\
\hline Lymphocytes & $1.56(1.12-1.96)$ & $0.755(0.5-1.12)$ & 0.001 \\
\hline Platelets & $229(159-266)$ & $192(150-218)$ & 0.014 \\
\hline CD3 & $985(812-1311)$ & $395(113-641)$ & 0.001 \\
\hline CD4 & $558(400-804)$ & $235(198-401)$ & 0.001 \\
\hline CD8 & $378(274-526)$ & $191(73-307)$ & $<0.001$ \\
\hline CD16 + CD56 & $104(70-196)$ & $98(58-183)$ & 0.13 \\
\hline CD19 & $152(117-251)$ & $154(76-256)$ & 0.176 \\
\hline \multicolumn{4}{|l|}{ Biochemical } \\
\hline AST, U/L & $22(15-33)$ & $26(21-48.5)$ & 0.01 \\
\hline$A L T, U / L$ & $26(13-54)$ & $29(23-55)$ & 0.06 \\
\hline ALP, U/L & $55.7(45-73)$ & $58(48.4-73)$ & 0.783 \\
\hline Total bilirubin, $\mu \mathrm{mol} / \mathrm{L}$ & $9(6.6-11.3)$ & $8.6(7-13.79)$ & 0.318 \\
\hline Direct bilirubin $\mu \mathrm{mol} / \mathrm{L}$ & $4(3.9-5)$ & $7.8(4.6-11.4)$ & 0.001 \\
\hline Albumin, $\mathrm{g} / \mathrm{L}$ & 38.8 (37-41.8) & $35.9(30.1-34.4)$ & 0.16 \\
\hline $\mathrm{BUN}, \mathrm{mmol} / \mathrm{L}$ & $4.04(3.924 .89)$ & $7.82(4.64-11.4)$ & 0.001 \\
\hline Creatinine, $\mu \mathrm{mol} / \mathrm{L}$ & $52(49-72)$ & $69(45.3-120.8)$ & 0.04 \\
\hline Creatinine kinase, $\mu \mathrm{M}$ & $60(39-89)$ & $69(54.5-158)$ & 0.055 \\
\hline CK-MB, U/L & $1.02(0.48-3.6)$ & $2.5(1.58-6.92)$ & 0.001 \\
\hline MYO, $\mu \mathrm{g} / \mathrm{L}$ & $89(21.4-97.4)$ & $97.8(48.3-234)$ & 0.071 \\
\hline CTnl, ng/mL & $0.006(0.005-0.03)$ & $0.034(0.015-0.426)$ & 0.001 \\
\hline ProBNP & $38.1(30.5-234)$ & $209(44-921)$ & $<0.001$ \\
\hline $\mathrm{LDH}, \mathrm{U} / \mathrm{L}$ & 199(161-253) & $355(264-589)$ & 0.002 \\
\hline
\end{tabular}




\begin{tabular}{|llll|}
\hline Variables & $\begin{array}{l}\text { Non-aggravation } \\
(\mathbf{n}=109)\end{array}$ & $\begin{array}{l}\text { Aggravation } \\
(\mathbf{n}=\mathbf{8 8})\end{array}$ & $\boldsymbol{p}$ value \\
\hline Potassium, mmol/L & $116(103-140)$ & $121(88-140)$ & 0.314 \\
\hline Sodium, mmol/L & $3.94(3.7-4.63)$ & $3.7(3.3-4.27)$ & 0.065 \\
\hline Coagulation function & & & \\
\hline PT, s & $11.2(11-11.9)$ & $12(11.7-13.4)$ & 0.059 \\
\hline APTT, s & $27.9(25.4-30.5)$ & $29.05(26.9-32)$ & 0.119 \\
\hline D-dimer, mg/mL & $0.32(0.15-0.8)$ & $6.03(0.9-18.6)$ & 0.001 \\
\hline Fbg, g/L & $2.87(2.18-4.3)$ & $3.63(3.0-4.94)$ & 0.001 \\
\hline Inflammation immunologic related indices & & 0.001 \\
\hline CRP, mg/L & $5(1-15.5)$ & $26.6(10.7-122)$ & 0.001 \\
\hline Serum ferritin, ng/mL & $258(208-303)$ & $288(254-699)$ & 0.01 \\
\hline Procalcitonin, ng/mL & $0.037(0.027-0.06)$ & $1.06(0.11-3.26)$ & 0.002 \\
\hline IL-6, pg/L & $16.7(14.4-20.4)$ & $25(17.6-64.5)$ & 0.42 \\
\hline IL-10, pg/L & $5.57(4.2-11.4)$ & $6.1(4.64-9.95)$ & 0.245 \\
\hline TNF, pg/L & $4.64(4.12-6)$ & $4.9(4.32-8.4)$ & \\
\hline Data are median (IQR), $\mathrm{n}(\%)$. & & \\
\hline
\end{tabular}

\section{Chest imaging features and pathogens examination}

The Chest imaging features on admission are summarized in Table 4. The median interval between symptom onset and CT examination was 7 days. Of the 197 patients with a chest CT scan on admission, the majority $(164,83.2 \%)$ showed abnormal results, consisting of 107 cases $(59.4 \%)$ of multiple groundglass opacities and 115 cases $(72.3 \%)$ of no bilateral lobular and subsegmental consolidation areas. $64.4 \%$ of patients showed diffuse infiltration or white lung in both lungs, and about $42.4 \%$ had diffuse patch shadow with interstitial involvement. Compared with the patients of non-aggravation, the aggravation group showed more bilateral ground-glass opacity and subsegmental areas of consolidation as well as the lung interstitial involvement. Most of the lesions were localized in the periphery then the center follows and the last was both the periphery and center of the lung $(105,53.3 \%$ vs $18,9.1 \%$ vs 74 , $37.6 \%)$. In the non-aggravation patients, the lesions were more localized in the periphery rather than the center of the lung. However, the lesions would spread to the center of bronchus and gradually to the whole lung in aggravation patients. Therefore, the lesion was more likely located in both the periphery and center of the lung in the disease progression group (54.5\% vs $23.9 \%$ ). The SARS-CoV-2 PCR assay demonstrated that $167(84.8 \%)$ cases showed positive results at the first test, and $30(15.2 \%)$ cases 
showed negative results. Besides SARS-CoV-2, we also detected other pathogens within the same patients, including epsteinbarr virus (EBV, 22, 13.90\%), mycoplasma pneumonia (32, 16.20\%), influenza B virus $(28,14.2 \%)$, parainfluenza virus $(17,8.6 \%)$, cytomegalovirus (CMV, 15, 7.6\%). There were no significant differences between the disease progression group and the control group.

Table 4

Radiological data and pathogens test of the patients.

\begin{tabular}{|c|c|c|c|c|}
\hline $\begin{array}{l}\text { Clinical } \\
\text { characteristics }\end{array}$ & $\begin{array}{l}\text { Total patients }(\mathrm{n}= \\
\text { 197) }\end{array}$ & $\begin{array}{l}\text { Non-aggravation }(n= \\
109)\end{array}$ & $\begin{array}{l}\text { Aggravation } \\
(n=88)\end{array}$ & $P$ \\
\hline Chest Imaging features & $164(83.2 \%)$ & $87(79.8 \%)$ & 77 (87.5\%) & 0.151 \\
\hline Ground-glass opacity & $107(59.4 \%)$ & $59(68.6 \%)$ & $48(54.5 \%)$ & 0.01 \\
\hline Consolidation & $115(72.3)$ & $62(65.3 \%)$ & $53(82.8 \%)$ & 0.015 \\
\hline Bilateral infiltration & $103(64.4 \%)$ & $47(51.1 \%)$ & $56(82.4 \%)$ & 0.01 \\
\hline Interstital involvement & $61(42.4 \%)$ & $32(35.6 \%)$ & $29(53.7 \%)$ & 0.03 \\
\hline \multicolumn{5}{|l|}{ Lesion location } \\
\hline Peripheral & $105(53.3 \%)$ & 75 (79.3\%) & $30(19.3 \%)$ & $\begin{array}{l}< \\
0.001\end{array}$ \\
\hline Central & $18(9.1 \%)$ & $8(6.7 \%)$ & $10(5.8 \%)$ & \\
\hline $\begin{array}{l}\text { Both peripheral and } \\
\text { central }\end{array}$ & $74(37.6 \%)$ & $26(39.6 \%)$ & $48(14.9 \%)$ & \\
\hline \multicolumn{5}{|l|}{ Pathogens test } \\
\hline $\begin{array}{l}\text { SARS-CoV-2 PCR } \\
\text { assay+ }\end{array}$ & $167(84.8 \%)$ & $93(85.3 \%)$ & $74(84.1 \%)$ & 0.81 \\
\hline $\begin{array}{l}\text { SARS-CoV-2 PCR } \\
\text { assay } \pm\end{array}$ & 30 (15.2\%) & $16(14.7 \%)$ & 14 (15.9\%) & 0.78 \\
\hline EBV & $22(13.9 \%)$ & $15(15.2 \%)$ & $7(11.9 \%)$ & 0.754 \\
\hline $\begin{array}{l}\text { Mycoplasma } \\
\text { pneumonia }\end{array}$ & $32(16.2 \%)$ & $23(21.1 \%)$ & $9(10.2 \%)$ & 0.426 \\
\hline Influenza B virus & $28(14.2 \%)$ & $15(13.8 \%)$ & $13(14.8 \%)$ & 0.84 \\
\hline Parainfluenza virus & $17(8.6 \%)$ & $9(8.3 \%)$ & $8(9.1 \%)$ & 0.836 \\
\hline CMV & $15(7.6 \%)$ & $8(7.3 \%)$ & $7(8 \%)$ & 0.871 \\
\hline
\end{tabular}

Nucleic acid testing is the standard method for the diagnosis of COVID-19 infections. However, some research suggested that this method usually showed lower positive rates due to poor RNA stability, 
different specimen position, and quality. Therefore, the IgM-IgG combined assay was recommended to increase the sensitivity of COVID-19 diagnoses especially in patients with suspected SARS-CoV-2 infection. In this study, the dynamic changes of IgM-IgG antibody levels were detected. The specific IgG and IgM antibodies can be detected 4-7 days after onset of illness. The IgM antibody titers increased sharply and notably in the initial two weeks and peaked at 1-2 week after symptom onset and significantly declined after 21 days. The IgG antibodies titers increased over time peaking at 4-5 week after onset of illness, and then maintained higher levels for the whole observation period (Fig. 1a). In addition, we compared the lgM-IgG levels between the two groups and found that there was no difference in the levels of IgM between the aggravation group and the non-aggravation group during the first two weeks. After that, the aggravation group tended to have a more vigorous IgM response against SARSCoV-2 and displayed a higher peak, which suggested that serum IgM antibody levels were significantly correlated with disease progression from day 3-week onward (Fig. 1b). However, the levels of IgG in aggravation group were markedly lower compared to the non-aggregation group in the early stage of infection, and then it experienced a rapid growth and exceed those of the non-aggravation group Fig. 1c.

\section{Treatments and clinical outcomes}

All of the confirmed patients were isolated and treated in a negative pressure ward with applicable protective equipment. Table 5. includes details of the outcomes associated with COVID-19 infections and treatments administered. Most patients received combination therapy with oxygen support, antibiotics, antiviral, and glucocorticoids. $139(68 \%)$ patients received multiple antiviral treatments including cephalosporins, quinolones, carbapenems, tigecycline. More than one intravenous antibiotic was given to $65(42.8 \%)$ patients and $87(57.2 \%)$ received an antibiotic only. The patients prescribed antibiotics treatment with a duration of $3-21$ days (median, 5 days [IQR 3-6]. Most patients $(155,83.8 \%$ ) were given antibiotic treatment including ganciclovir, oseltamivir, ritonavir, and lopinavir with a median duration of 5 days [IQR 3-8]. Among the 86 patients who required systemic glucocorticoid therapy (methylprednisolone, dexamethasone) over the treatment period, 49 (57\%) patients were given low-dose glucocorticoids and $37(43 \%)$ were given standard-dose glucocorticoids at the initiation of treatment. The median time on glucocorticoid therapy was 7.5 days [IQR 5-13]. 21 (61.4\%) received Chinese traditional medicine treatment, which has been demonstrated to play an important role in resistance to viral infections. The duration of Chinese medicine treatment was 9 days [IQR 6.5-15]. Of the 197 patients, more than two-thirds of the patients required oxygen therapy. $105(55.6 \%)$ patients were treated with highflow oxygen. 43(44.8\%) were given non-invasive mechanical ventilation to assist ventilation for 4 days [IQR 5-13]. And 23(25.6\%) patients used invasive mechanical ventilation (4d [IQR 2-10]) respectively. The study also indicated that antibiotics, corticosteroids and oxygen therapy were necessary more often in the aggregation patients than in the non-aggregation patients $(50.5 \%$ vs $89.8 \%, 28.90 \%$ vs $69.00 \%$, $42.60 \%$ vs $100.0 \%$ ). 
Table 5

Treatment and outcome of COVID-19 patients.

\begin{tabular}{|c|c|c|c|c|}
\hline Treatments & Total & Non-aggravation & Aggravation & $p$ value \\
\hline Antibiotics (n/\%) & $139(68 \%)$ & $55(50.5 \%)$ & $79(89.8 \%)$ & $<0.001$ \\
\hline Treatment period (d) & $6(4-9)$ & $5(3-9)$ & $8(6-12)$ & 0.001 \\
\hline Antiviral (n/\%) & $155(83.8 \%)$ & $91(83.5 \%)$ & $74(85.2 \%)$ & 0.12 \\
\hline Treatment period (d) & $5(3-8)$ & $6(3-7)$ & $7(3.75-9)$ & 0.07 \\
\hline Corticosteroids (n/\%) & $86(48.6 \%)$ & $26(28.9 \%)$ & $60(69 \%)$ & 0.01 \\
\hline Treatment period (d) & $7.5(5-13)$ & $7(5-8.5)$ & $11(6-15)$ & 0.001 \\
\hline Interferon (n/\%) & $134(68.4 \%)$ & $66(61.1 \%)$ & $68(77.3 \%)$ & 0.08 \\
\hline Treatment period (d) & $7(5-11)$ & $7(4.25-11)$ & $8(5-13)$ & 0.155 \\
\hline Chinese medicine (n/\%) & $121(61.4 \%)$ & $64(58.7 \%)$ & $57(64.8 \%)$ & 0.385 \\
\hline Treatment period (d) & $9(6.5-15)$ & $9(6-15)$ & $9(7-15)$ & 0.681 \\
\hline Oxygen treatment (n/\%) & $134(68.4 \%)$ & $46(42.6 \%)$ & $88(100 \%)$ & $<0.001$ \\
\hline High-flow oxygen therapy (n/\%) & $105(55.6 \%)$ & $40(39.2 \%)$ & $65(74.7 \%)$ & 0.001 \\
\hline Treatment period (d) & $5.5(4-18.5)$ & $7(4-15)$ & $8(5-13.5)$ & 0.149 \\
\hline $\begin{array}{l}\text { Noninvasive mechanical } \\
\text { ventilation }(n / \%)\end{array}$ & $43(44.8 \%)$ & $1(4.2 \%)$ & $42(58.3 \%)$ & 0.001 \\
\hline Treatment period (d) & $7(5-13)$ & - & $7(5-13)$ & - \\
\hline Invasive mechanical ventilation & $23(25.6 \%)$ & $2(7.7 \%)$ & $21(32.8 \%)$ & 0.013 \\
\hline Treatment period (d) & $4(2-10)$ & - & $4(2-10)$ & - \\
\hline \multicolumn{5}{|l|}{ Outcomes (n/\%) } \\
\hline ARDS & $59(34 \%)$ & $10(11.5 \%)$ & 49 (59\%) & 0.01 \\
\hline Septic shock & $29(17.4 \%)$ & $9(10.2 \%)$ & $20(25.3 \%)$ & 0.01 \\
\hline DIC & $15(7.8 \%)$ & $3(2.9 \%)$ & $12(13.6 \%)$ & 0.005 \\
\hline Fungal infections & $27(16.4 \%)$ & $11(12 \%)$ & $16(21.9 \%)$ & 0.81 \\
\hline Acute cardiac injury & $32(18 \%)$ & $11(11.6 \%)$ & $21(25.3 \%)$ & 0.017 \\
\hline Acute kidney injury & $25(14 \%)$ & $5(5.3 \%)$ & $20(24.1 \%)$ & 0.02 \\
\hline ICU admission & $57(28.9 \%)$ & 8 (7.34\%) & 49 (55.7\%) & $<0.001$ \\
\hline
\end{tabular}




\begin{tabular}{|lllll|}
\hline Treatments & Total & Non-aggravation & Aggravation & $p$ value \\
\hline Length of ICU stay (d) & $7(2-13)$ & $5(2-8)$ & $7(2-13)$ & 0.15 \\
\hline Length of hospital stay (d) & $14(9-21)$ & $10(9-19)$ & $15(13-22)$ & 0.003 \\
\hline $\begin{array}{l}\text { Duration of viral shedding } \\
\text { after onset (d) }\end{array}$ & $11(6.5-17)$ & $9(6-14)$ & $13(8-18)$ & 0.039 \\
\hline Data are median (IQR), $\mathrm{n}(\%)$. & & & & \\
\hline
\end{tabular}

By the end of Mar 10, 151 (77\%) patients were improved and discharged. The median length of stay of discharged patients was 14 days [IQR 9-21]. 46 (23\%) patients had died from ARDS, shock and multiple organ damage. Of the 88 aggravation patients, 49 (55.7\%) patients were admitted to the ICU for 8 days, which was significantly higher than that of the non-aggravation patients $(5,5.3 \%)$ for 5 days. To evaluate the prognosis of COVID-19 patients, we performed the Kaplan-Meier analysis, and the composite endpoint (event) was ICU transfer or death within 25 days from the date of admission to the hospital. The cumulative event-free survival curve was plotted in Fig. $1 \mathrm{~d}$, which suggested that $61.6 \%$ of patients had not experienced ICU transfer or survival from the hospital. During the course of the disease, about 103 (52.3\%) patients presented with functional damage involving multiple vital organs, including ARDS (59, $34 \%)$, septic shock $(29,17.4 \%)$, DIC $(15,7.8 \%)$, fungal infections $(27,16.4 \%)$, acute cardiac injury (32, $18 \%)$, and acute kidney injury $(25,14 \%)$. And patients with disease progression showed higher complication rates than that of the patients without Table 5 .

\section{Risk factors for disease progression}

To investigate the risk factors for disease progression, we compared the epidemiological, clinical characteristics, laboratory, and radiological findings of COVID-19 patients between the two groups. In univariate logistic regression analysis, we found that the older age, male, underlying diseases (hypertension, diabetes), dyspnea, chest tightness were more frequently administered to patients in the progression group. It revealed that lymphopenia, neutrophilia, high levels of AST, lactic acid, Urea, Creatinine kinase, LDH, CTnl, ProBNP, Fbg, D-dimer, Serum ferritin, Procalcitonin, IL-6 were all significantly correlated with disease progression. Then, these variables were included in the multivariable logistic regression model, which indicated that older age, hypertension, diabetes, dyspnea, lymphocytes, Fbg, LDH, CTnl, serum ferritin, IL-6 were all independently associated with disease progression Table 6. 
Table 6

Bivariate cox regression of factors associated with disease progression of COVID-19.

\begin{tabular}{|c|c|c|c|c|c|c|}
\hline \multirow[t]{2}{*}{ Variables } & \multicolumn{3}{|c|}{ Univariate analysis } & \multicolumn{3}{|c|}{ Multivariate analysis } \\
\hline & OR & $95 \% \mathrm{Cl}$ & $\mathbf{P}$ & OR & $95 \% \mathrm{Cl}$ & $\mathbf{P}$ \\
\hline Age ( $\geq 60$ years vs. $<60$ years) & 4.17 & $2.3-7.59$ & $<0.001$ & 2.74 & $1.03-7.27$ & 0.04 \\
\hline Gender (male vs female) & 1.91 & $1.06-3.45$ & 0.03 & 1.03 & $0.99-1.07$ & 0.09 \\
\hline \multicolumn{7}{|l|}{ Comorbidity (yes vs no) } \\
\hline Hypertension & 3.00 & $1.46-6.19$ & 0.002 & 3.64 & $1.28-10.3$ & 0.015 \\
\hline Diabetes & 2.17 & $1.13-4.15$ & 0.001 & 8.31 & $2.92-23.6$ & 0.001 \\
\hline \multicolumn{7}{|l|}{ Signs and symptoms (yes vs no) } \\
\hline Dyspnea & 2.01 & $1.13-3.61$ & 0.018 & 6.17 & $2.01-18.9$ & 0.001 \\
\hline Chest distress & 3.0 & $1.51-6.01$ & 0.001 & 1.85 & $0.76-4.5$ & 0.18 \\
\hline \multicolumn{7}{|l|}{ Hematologic } \\
\hline Neutrophils & 6.83 & $3.53-17.6$ & $<0.001$ & 0.99 & $0.96-1.01$ & 0.41 \\
\hline Lymphocytes & 8.58 & $4.5-16.3$ & 0.001 & 0.29 & $0.10-0.86$ & 0.02 \\
\hline CD3 & 0.08 & $0.04-0.17$ & 0.002 & 0.101 & $0.01-1.78$ & 0.12 \\
\hline CD4 & 0.74 & $0.59-0.93$ & 0.01 & 0.88 & $0.21-3.7$ & 0.86 \\
\hline CD8 & 0.25 & $0.13-0.49$ & 0.03 & 1.01 & $0.99-1.03$ & 0.16 \\
\hline \multicolumn{7}{|l|}{ Coagulation function } \\
\hline $\mathrm{Fbg}$ & 4.35 & $2.33-8.14$ & 0.002 & 9.72 & $2.6-36.4$ & 0.001 \\
\hline D-dimer & 9.59 & $4.48-20.51$ & $<0.001$ & 1.75 & $0.37-8.24$ & 0.48 \\
\hline \multicolumn{7}{|l|}{ Biochemical } \\
\hline AST & 2.09 & $1.11-3.93$ & 0.03 & 0.99 & $0.93-1.07$ & 0.98 \\
\hline lactic acid & 2.6 & $1.363-4.96$ & 0.001 & 1.75 & $0.37-8.24$ & 0.47 \\
\hline Urea & 5.17 & $2.66-10$ & 0.001 & 1.19 & $0.96-1.46$ & 0.11 \\
\hline Creatinine kinase & 11.67 & $2.58-52.8$ & 0.001 & 1.09 & $0.96-1.24$ & 0.19 \\
\hline LDH & 8.6 & $4.43-16.69$ & 0.001 & 1.01 & $1-1.02$ & 0.046 \\
\hline CTnl & 4.78 & $2.15-10.6$ & 0.002 & 10.06 & $2.44-41.2$ & 0.001 \\
\hline ProBNP & 5.89 & $3.64-9.04$ & 0.001 & 0.10 & $0.93-1.07$ & 0.98 \\
\hline
\end{tabular}




\begin{tabular}{|lllllll|}
\hline Variables & \multicolumn{3}{c}{ Univariate analysis } & \multicolumn{4}{c|}{ Multivariate analysis } \\
\cline { 2 - 7 } & OR & $\mathbf{9 5 \%}$ Cl & P & OR & $95 \%$ Cl & P \\
\hline IL-6 & 3.26 & $1.77-5.99$ & 0.001 & 1.03 & $1.01-1.06$ & 0.02 \\
\hline CRP & 5.99 & $1.18-30.3$ & 0.03 & 1.01 & $0.99-1.03$ & 0.33 \\
\hline PCT & 3.73 & $1.96-7.12$ & 0.001 & 2.11 & $0.67-6.62$ & 0.2 \\
\hline Serum ferritin & 2.30 & $1.26-4.2$ & 0.006 & 1.01 & $1.0-1.02$ & 0.04 \\
\hline
\end{tabular}

\section{Discussion}

The present study included a total of 197 patients who were hospitalized with COVID-19 from Jan 25, 2020 , to Mar 15, 2020. All of the patients were evaluated for therapeutic efficacy after at least one week of hospitalization. The results identified disease progression in 88 patients and non-progression in 109 patients. We summarized the clinical characteristics and identified several risk factors associated with disease progression in patients. Most of them received timely diagnosis and treatment as the government formulated an efficient early warning and isolation program in time. As of Mar 15, 2020, 151 (77.7\%) patients were improved and discharged and $46(23.4 \%)$ patients had died. Though all age groups have been affected by COVID-19, the elderly patients (over 60 years old) have a greater risk for infection and a relatively high proportion of severe and disease progression cases (14-18). Consistent with previous studies, males were identified more likely to be contamination with the virus (39.1\%women versus $60.9 \%$ men), and have severe progression (60.3\%). Fewer cases have been identified among children and infants. Our study showed that advanced age is the independent risk factor for disease progression.

Of all patients, $72(36.5 \%)$ cases had one or more underlying diseases including diabetes, hypertension, COPD. The logistic regression analysis showed a significantly increased number of patients with diabetes, hypertension in disease progression groups than that of the non-progression group. It has been reported that patients with hypertension or diabetes accounted for $20-30 \%$ of total infected patients and comprised of over half of patients in ICU (19-21). Recently, a retrospective cohort study also demonstrated that these comorbidities have been responsible for $60.9 \%$ of deaths caused by COVID-19 (22). A large number of studies have indicated that the Angiotensin-converting enzyme 2 (ACE2) receptor is highly expressed in the cardiovascular/cerebrovascular and lung tissue in the hypertension patients (23). In addition, ACE2 is one of the most important host receptors of H7N9, SARS and COVID-19, whose activity is closely related to the pathogenesis of inflammatory and acute injury of lung disease caused by these viruses (24-26). Given that experimental studies suggested that the spikes of SARS-CoV-2 could bind to the ACE2 receptors, which mediated virus entry into of HeLa cells and viral replication $(22,27)$. Some scholars have found that most of COVID-19 patients showed higher activity of angiotensin II compared to the uninfected people, and the abnormal increase in angiotensin II was related to lung failure and death $(28,29)$. ACEls and ARBs are recommended for the management of hypertension and renal disease associated with diabetes (30). Recent studies have reported that the application of ACE 
inhibitor could induce a marked increase expression of ACE2 expression, which means that ACEIs/ ARBs would increase the risk of infection of SARS-CoV-2 and disease progression of COVID-19 in hypertension and diabetes patients receiving these drugs $(31,32)$. In the present study, COVID-19 patients with ACEI/ARB therapy were enrolled, and we found that there are more patients taking ACEl/ARB in the progression group. Therefore, taking ACEI/ARB may be another potential risk factor for disease progression of COVID-19.

In our cohort, no significant difference in the median days from symptom onset to hospital admission was found between the disease progression and non-progression patients. Consistent with the symptom reported before $(20,33)$, the most common symptoms are fever, cough, fatigue, chest tightness, and myalgia or arthralgia. The proportion of patients with myalgia or arthralgia, chest distress and dyspnea was significantly higher in the disease progression group. Remarkably, few patients exhibited some less common symptomatology including abdominal pain, vomiting, and conjunctival hyperemia, which may result in missed diagnosis and transmission to other people. Previous studies found that virus could be detected in stool samples in the patients with symptoms of abdominal pain, vomiting, or asymptomatic $(34,35)$. Therefore, further research is still required to determine whether fecal oral transmission exists. In our study, no significant difference was identified between the two groups regarding this uncommon symptomatology.

SARS-CoV-2 induced immune responses and infection cytokine storms are believed to play major roles in disease progression $(36,37)$. The destruction of lung cells recruit macrophages and monocytes, trigger the adaptive $T$ and $B$ cell immune responses, and release cytokines to resolve the infection and even mediate widespread excessive inflammation at the same time $(38,39)$. In the present study, $92(46.7 \%)$ patients showed significantly neutrophilia and lymphopenia with pronounced reduction of peripheral blood $\mathrm{CD}^{+}, \mathrm{CD}^{+}$, and $\mathrm{CD} 8^{+}$cells. And, the lymphocyte subsets, especially $\mathrm{CD} 3^{+}, \mathrm{CD} 4^{+}$, impaired more severely in the disease progression patients. ,This is consistent with the previous study by Qin et al, which demonstrated that the percentage of memory, regulatory and effector T cells were significantly decreased in severe cases when compared to non-severe cases $(38,40)$. Previous studies have shown that serum inflammation-related indices were closely related to the degree of inflammation and disease severity (41). In this study, compared with patients without disease progression, the disease progression patients showed significantly increased expression of inflammation-related factors including IL6, CRP, serum ferritin, procalcitonin. And the multivariate analysis revealed that the elevated level of IL6, serum ferritin, were the risk factors of disease progression patients.

It is previously established that patients with severe SARS and MERS had a higher incidence of multiple organ dysfunction syndromes including liver damage, acute heart/kidney injury, coagulation dysfunction, and even death $(42,43)$. And a lot of research has shown the clinical characteristics and laboratory findings associated with different degrees of multiple organs in patients with COVID-19 $(17,42,44)$. In our study, liver damage and acute heart/kidney injury had been considered to occur in more than a third of patients. The level of AST, ALT, direct bilirubin, LDH, Creatinine, BUN, CTnI, ProBNP seemed to be significantly higher in patients with disease progression. The multivariate analysis revealed that the 
elevated level of LDH, CTnl, ProBNP were the risk factors for patients with disease progression. Presently, there are three potential mechanisms for this observation: firstly, SARS-CoV-2 binding to ACE2 positive cells mediated direct damage; Secondly, systemic inflammatory response syndrome including cytokine storm, dysregulated immunocytes, and uncontrolled inflammation; Thirdly, exogenous drugs induced organ metabolizing burden, or worsening organ function $(45,46)$. Recently, the coagulation dysfunction has attracted more and more attention among scholars. It has been reported that the incidence of coagulopathy in all patients showed abnormalities of varying degrees in coagulation function parameters. A previous study revealed that Fbg and D-dimer elevation were related to the severity of the disease (47). And Ji et al. demonstrated that coagulation activation and hyper-fibrinolysis were coexistent in patients with severe COVID-19 infection (48). And patients with elevated plasmin and Fbg may have an increased risk of ARDS and mortality (49). In this study, we found that the incidence of abnormalities in coagulation function parameters (APTT, Fbg, D-dimer) was higher in patients with disease progression compared to the improved patients. Further analysis revealed that the elevated level of Fbg was significantly associated with the outcome. Therefore, measurements of these coagulation function parameters may be important biomarkers of disease progression and outcome.

Until now, no specialized antiviral treatment has been identified for COVID-19 infection, except for meticulous supportive care. Currently available treatment approaches include symptomatic and supportive therapies, such as oxygen therapy, antivirals, prevention and treatment of infections, and combination treatment with glucocorticoids $(50,51)$. Prior studies have suggested that patients with SARS-CoV would benefit from the combination of lopinavir and ritonavir with fewer adverse clinical outcomes $(52,53)$. And some preclinical research suggested that remdesivir have broad-spectrum antiviral activity for MERS-CoV and SARS-CoV1/2 infections (54). However, further studies on a larger set of clinical specimens will be required to assess the efficacy and safety of antiviral drugs $(52,55,56)$. Due to the cytokine storm associated with COVID-19, corticosteroids were widely used in the treatment of patients with severe illness to attenuate inflammation associated with lung injury. Nevertheless, some researchers refuted that the use of glucocorticoids did not reduce mortality, but could easily lead to the disease progression and increase the risk of secondary infections (57). Therefore, the rational use of an appropriate dose of glucocorticoids could suppress the excessive activation of immune system and secretion of inflammatory cytokines. In our study, most patients received combination therapy with oxygen support, antibiotics, antiviral, and glucocorticoids. Almost of patients received respiratory support including nasal cannula oxygen and continuous positive air pressure. The progression group was significantly more likely to receive higher levels of respiratory support. Without a doubt, patients with disease progression have a higher mortality rate than patients without disease progression. And ARDS remained the most common cause of death, followed by multiple organ failure. Therefore, the prevention and treatment of ARDS represent an important strategic objective for the reduction of mortality and morbidity.

\section{Limitations}


The study also has severe important limitations. Firstly, the inherent shortcomings belong to a retrospective observational study, small sample size and short term follow-up make it difficult to reach a firm conclusion. Secondly, our institution was only the specified hospital for severe patients during the early outbreak, which could have resulted in some selection bias. Therefore, a larger cohort study of patients from China and other countries may help to further investigate the clinical characteristics and risk factors for the outcome. Finally, the actual duration of viral clearance was overrated owing to the frequency of respiratory specimen collection. In addition, the viral load of the SARS-CoV-2 was not quantified accurately, and false-negative results for an upper respiratory sample have also been reported. Therefore, studies on the dynamic characteristics of the viral load are still warranted.

\section{Conclusion}

\section{Conclusions}

The outbreak of 2019 coronavirus disease (COVID-19) has become an unprecedented global health crisis with over 6 million confirmed cases and 380,000 deaths worldwide. Investigating the potential factors of advanced age, comorbidities and elevated level of IL-6, serum ferritin enables early identification of patients with poor prognosis. Detection of the dynamic antibody may offer vital clinical information during the course of SARS-CoV-2 and provide prognostic value or even foreseeable therapeutic options for patients infection. However, a larger cohort study of patients from China and other countries may help to further investigate the clinical characteristics and risk factors for the outcome.

\section{Abbreviations}

ALT, alanine aminotransferase; APTT, activated partial thromboplastin time; AST, aspartate aminotransferase; CK-MB, creatine kinase muscle-brain isoform; CRP, C-reactive protein; IL-6, interleukin-6; IQR, interquartile range; LDH, lactate dehydrogenase; PT, prothrombin time; WBC: white blood cell; CT: computed tomography; ARDS, acute respiratory distress syndrome. WHO, World Health Organization; COPD, chronic obstructive pulmonary disease; ARDS, acute respiratory distress syndrome; IQR, interquartile ranges; CTnl, Cardiac troponin I; DBIL, direct bilirubin; TBIL, total bilirubin; PCT, procalcitoni; Fbg, fibrinogen; CMV, cytomegalovirus; ACE2, Angiotensin-converting enzyme 2.

\section{Declarations}

Ethics approval and consent to participate: All participants provided written informed consent before data were collected retrospectively.

Consent for publication: Not applicable.

Availability of data and materials: This study was conducted in accordance with the Declaration of Helsinki and was approved by the Institutional Review Board of Taihe and Jinzhou central hospital, and all participants provided written informed consent before data were collected retrospectively. 
Competing interests: The authors declare that they have no competing interests.

Funding: Not applicable.

Authors' contributions: Maojun Di, Qiang Tang conceived and designed the manuscript. Qiang Tang, Yanwei Liu wrote the manuscript. Yingfeng Fu, Kailiang Xu, Ziyang Di, Bo Tang; investigation, Shengbo Han, Yingfeng Fu, Yanwei Liu, Hui Wu gave the final approval of the manuscript. All authors have read and agreed to the published version of the manuscript.

Acknowledgements: Not applicable.

Authors' information: ${ }^{1}$ Department of General Surgery, Shiyan Taihe Hospital, Hubei University of Medicine, Shiyan, Hubei Province, China; ${ }^{2}$ Tianjin Medical University Cancer Institute and Hospital, National Clinical Research Center for Cancer, Key Laboratory of Cancer Prevention and Therapy, Tianjin, China; ${ }^{3}$ Department of Urology, Jingzhou Central Hospital, the Second Clinical Medical College, Yangtze University, Jingzhou 434020; ${ }^{4}$ School of Public Health, Xinxiang Medical University, Henan, China

\section{References}

1. WHO. WHO characterizes COVID-19 as a pandemic Published March 13. 2020. Available from: https://www.who.int/emergencies/diseases/novel-coronavirus-2019/events-as-they-happen.

2. Zhang $\mathrm{N}$, Wang L, Deng $\mathrm{X}$, Liang $\mathrm{R}$, Su M, He C, et al. Recent advances in the detection of respiratory virus infection in humans. J Med Virol. 2020;92(4):408-17.

3. Zhu N, Zhang D, Wang W, Li X, Yang B, Song J, et al. A Novel Coronavirus from Patients with Pneumonia in China, 2019. N Engl J Med. 2020;382(8):727-33.

4. Yin Y, Wunderink RA-O, MERS. SARS and other coronaviruses as causes of pneumonia. (1440-1843 (Electronic)).

5. Li-Li R, Ye-Ming W, Zhi-Qiang W, Zi-Chun X, Li G, Teng X, et al. Identification of a novel coronavirus causing severe pneumonia in human: a descriptive study. Chinese medical journal. 2020.

6. Zaki AM, van Boheemen S, Bestebroer TM, Osterhaus AD, Fouchier RA. Isolation of a novel coronavirus from a man with pneumonia in Saudi Arabia. N Engl J Med. 2012;367(19):1814-20.

7. Vijgen L, Keyaerts E, Zlateva K, Van Ranst M. Identification of six new polymorphisms in the human coronavirus 229E receptor gene (aminopeptidase N/CD13). International journal of infectious diseases: IJID : official publication of the International Society for Infectious Diseases. 2004;8(4):217-22.

8. Waites KB, Xiao L, Liu Y, Balish MF, Atkinson TP. Mycoplasma pneumoniae from the Respiratory Tract and Beyond. (1098-6618 (Electronic)).

9. Chan JF, Yuan S, Kok KH, To KK, Chu H, Yang J, et al. A familial cluster of pneumonia associated with the 2019 novel coronavirus indicating person-to-person transmission: a study of a family cluster. Lancet. 2020;395(10223):514-23. 
10. Wang L, Wang Y, Ye D, Liu Q. Review of the 2019 novel coronavirus (SARS-CoV-2) based on current evidence. (1872-7913 (Electronic)).

11. Zu ZY, Jiang MD, Xu PP, Chen W, Ni QQ, Lu GM, et al. Coronavirus Disease 2019 (COVID-19): A Perspective from China. Radiology. 2020(1527 - 1315 (Electronic)):200490.

12. Wu C, Chen X, Cai Y, Xia J, Zhou X, Xu S, et al. Risk Factors Associated With Acute Respiratory Distress Syndrome and Death in Patients With Coronavirus Disease 2019 Pneumonia in Wuhan, China. LID - 10.1001/jamainternmed.2020.0994 [doi] LID - e200994. 2020(2168-6114 (Electronic)).

13. Leung C. Risk factors for predicting mortality in elderly patients with COVID-19: A review of clinical data in China. (1872-6216 (Electronic)).

14. Huang C, Wang Y, Li X, Ren L, Zhao J, Hu Y, et al. Clinical features of patients infected with 2019 novel coronavirus in Wuhan, China. Lancet. 2020;395(10223):497-506.

15. Chen T, Dai Z, Mo P, Li X, Ma Z, Song S, et al. Clinical characteristics and outcomes of older patients with coronavirus disease 2019 (COVID-19) in Wuhan, China (2019): a single-centered, retrospective study. LID - 10.1093/gerona/glaa089 [doi] LID - glaa089. 2020(1758-535X (Electronic)).

16. Guan WJ, Ni ZY, Hu Y, Liang WH, Ou CQ, He JX, et al. Clinical Characteristics of Coronavirus Disease 2019 in China. N Engl J Med. 2020;382(18):1708-20.

17. Wang D, Hu B, Hu C, Zhu F, Liu X, Zhang J, et al. Clinical Characteristics of 138 Hospitalized Patients With 2019 Novel Coronavirus-Infected Pneumonia in Wuhan, China. 2020(1538-3598 (Electronic)).

18. Arentz M, Yim E, Klaff L, Lokhandwala S, Riedo FX, Chong M, et al. Characteristics and Outcomes of 21 Critically III Patients With COVID-19 in Washington State. JAMA. 2020(1538-3598 (Electronic)).

19. Li B, Yang J, Zhao F, Zhi L, Wang X, Liu L, et al. Prevalence and impact of cardiovascular metabolic diseases on COVID-19 in China. Clinical research in cardiology: official journal of the German Cardiac Society. 2020;109(5):531-8.

20. Wu Z, McGoogan JM. Characteristics of and Important Lessons From the Coronavirus Disease 2019 (COVID-19) Outbreak in China: Summary of a Report of 72314 Cases From the Chinese Center for Disease Control and Prevention. LID - 10.1001/jama.2020.2648 [doi] FAU - Wu, Zunyou. 2020(1538-3598 (Electronic)).

21. Zhou F, Yu T, Du R, Fan G, Liu Y, Liu Z, et al. Clinical course and risk factors for mortality of adult inpatients with COVID-19 in Wuhan, China: a retrospective cohort study. Lancet. 2020;395(10229):1054-62.

22. Li G, Hu R, Zhang X. Antihypertensive treatment with ACEI/ARB of patients with COVID-19 complicated by hypertension. Hypertension research: official journal of the Japanese Society of Hypertension. 2020;43(6):588-90.

23. Hamming I, Timens W, Bulthuis ML, Lely AT, Navis G, van Goor H. Tissue distribution of ACE2 protein, the functional receptor for SARS coronavirus. A first step in understanding SARS pathogenesis. $J$ Pathol. 2004;203(2):631-7.

24. Kuhn JH, Li W, Choe H, Farzan M. Angiotensin-converting enzyme 2: a functional receptor for SARS coronavirus. Cell Mol Life Sci. 2004;61(21):2738-43. 
25. Santos RA-O, Sampaio WO, Alzamora AC, Motta-Santos DA-O, Alenina NA-O, Bader M, et al. The ACE2/Angiotensin-(1-7)/MAS Axis of the Renin-Angiotensin System: Focus on Angiotensin-(1-7). 2020(1522 - 1210 (Electronic)).

26. Zou Z, Yan Y, Shu Y, Gao R, Sun Y, Li X, et al. Angiotensin-converting enzyme 2 protects from lethal avian influenza A H5N1 infections. Nature communications. 2014;5(2041 - 1723 (Electronic)):3594.

27. Chan JF, Kok KH, Zhu Z, Chu H, To KK, Yuan S, et al. Genomic characterization of the 2019 novel human-pathogenic coronavirus isolated from a patient with atypical pneumonia after visiting Wuhan. Emerg Microbes Infect. 2020;9(1):221-36.

28. Watkins J. Preventing a covid-19 pandemic. BMJ. 2020;368:m810.

29. Vaduganathan M, Vardeny O, Michel T, McMurray JJV, Pfeffer MA, Solomon SD. Renin-AngiotensinAldosterone System Inhibitors in Patients with Covid-19. N Engl J Med. 2020;382(17):1653-9.

30. Agata J, Ura N, Fau - Yoshida H, Yoshida H, Fau - Shinshi Y, Shinshi Y, Fau - Sasaki H, Sasaki H, Fau Hyakkoku M, Hyakkoku M, Fau - Taniguchi S, et al. Olmesartan is an angiotensin II receptor blocker with an inhibitory effect on angiotensin-converting enzyme. 2006(0916-9636 (Print)).

31. Kuba K, Imai Y, Fau - Rao S, Rao S, Fau - Gao H, Gao H, Fau - Guo F, Guo F, Fau - Guan B, Guan B, Fau - Huan $Y$, et al. A crucial role of angiotensin converting enzyme 2 (ACE2) in SARS coronavirusinduced lung injury. (1078-8956 (Print)).

32. Zou Z, Yan Y, Shu Y, Gao R, Sun Y, Li X, et al. Angiotensin-converting enzyme 2 protects from lethal avian influenza A H5N1 infections. (2041 - 1723 (Electronic)).

33. Gayam V, Konala VM, Naramala SA-OX, Garlapati PR, Merghani MA, Regmi N, et al. Presenting characteristics, comorbidities, and outcomes of patients coinfected with COVID-19 and Mycoplasma pneumoniae in the USA. LID - 10.1002/jmv.26026 [doi]. (1096-9071 (Electronic)).

34. Tang A, Fau - Tong Z-D, Tong Zd Fau - Wang H-L, Wang HI Fau - Dai Y-X. Dai Yx Fau - Li K-F, Li Kf Fau - Liu J-N, Liu Jn Fau - Wu W-J, et al. Detection of Novel Coronavirus by RT-PCR in Stool Specimen from Asymptomatic Child, China. (1080-6059 (Electronic)).

35. Hindson J. COVID-19: faecal-oral transmission? Nature Reviews Gastroenterology Hepatology. 2020;17(5):259-.

36. Mazzoni A, Salvati L, Maggi L, Capone M, Vanni A, Spinicci M, et al. Impaired immune cell cytotoxicity in severe COVID-19 is IL-6 dependent. LID - 138554 [pii] LID - 10.1172/JCI138554 [doi]. 2020(1558-8238 (Electronic)).

37. Wong CK, Lam Cw Fau - Wu AKL. Wu Ak Fau - Ip WK, Ip Wk Fau - Lee NLS, Lee NI Fau - Chan IHS, Chan Ih Fau - Lit LCW, et al. Plasma inflammatory cytokines and chemokines in severe acute respiratory syndrome. (0009-9104 (Print)).

38. Qin C, Zhou L, Hu Z, Zhang S, Yang S, Tao Y, et al. Dysregulation of immune response in patients with COVID-19 in Wuhan, China. LID - 10.1093/cid/ciaa248 [doi] LID - ciaa248. 2020(1537-6591 (Electronic)).

39. Min CK, Cheon S, Ha NY, Sohn KM, Kim Y, Aigerim A, et al. Comparative and kinetic analysis of viral shedding and immunological responses in MERS patients representing a broad spectrum of disease 
severity. Sci Rep. 2016;6(2045-2322 (Electronic)):25359..

40. Tay MZ, Poh CM, Renia L, MacAry PA, Ng LFP. The trinity of COVID-19: immunity, inflammation and intervention. Nature reviews Immunology. 2020;20(6):363-74.

41. Min CK, Cheon S, Ha NY, Sohn KM, Kim Y, Aigerim A, et al. Comparative and kinetic analysis of viral shedding and immunological responses in MERS patients representing a broad spectrum of disease severity. (2045-2322 (Electronic)).

42. Cardoso FS, Pereira R, Germano N. Liver injury in critically ill patients with COVID-19: a case series. Critical care. 2020;24(1):190.

43. Gopalakrishnan A, Mossaid A, Lo KB, Vasudevan V, McCullough PA, Rangaswami J. Fulminant Acute Kidney Injury in a Young Patient with Novel Coronavirus 2019. Cardiorenal medicine. 2020(16645502 (Electronic)):1-6.

44. Cremer PC. SARS-CoV-2 and myocardial injury: Few answers, many questions. Cleveland Clinic Journal of Medicine. 2020.

45. Li Y, Xiao SA-OX. Hepatic involvement in COVID-19 patients: Pathology, pathogenesis, and clinical implications. LID - 10.1002/jmv.25973 [doi]. 2020(1096-9071 (Electronic)).

46. Channappanavar R, Perlman S. Pathogenic human coronavirus infections: causes and consequences of cytokine storm and immunopathology. (1863-2300 (Electronic)).

47. Ji HL, Zhao R, Matalon S, Matthay MA. Elevated Plasmin(ogen) as a Common Risk Factor for COVID19 Susceptibility. 2020(1522 - 1210 (Electronic)).

48. Prabhakaran P, Ware LB, White KE, Cross MT, Matthay MA, Olman MA. Elevated levels of plasminogen activator inhibitor-1 in pulmonary edema fluid are associated with mortality in acute lung injury. American journal of physiology Lung cellular molecular physiology. 2003;285(1):L20-8.

49. Idell S, James Kk Fau - Levin EG. Levin Eg Fau - Schwartz BS, Schwartz Bs Fau - Manchanda N, Manchanda N Fau - Maunder RJ, Maunder Rj Fau - Martin TR, et al. Local abnormalities in coagulation and fibrinolytic pathways predispose to alveolar fibrin deposition in the adult respiratory distress syndrome. (0021-9738 (Print)).

50. Li W, Yang Y, Liu ZH, Zhao YJ, Zhang Q, Zhang L, et al. Progression of Mental Health Services during the COVID-19 Outbreak in China. Int J Biol Sci. 2020;16(10):1732-8.

51. Kang S, Peng W, Zhu Y, Lu S, Zhou M, Lin W, et al. Recent progress in understanding 2019 novel coronavirus (SARS-CoV-2) associated with human respiratory disease: detection, mechanisms and treatment. Int J Antimicrob Agents. 2020;55(5):105950.

52. Ahn DG, Shin HJ, Kim MH, Lee S, Kim HS, Myoung J, et al. Current Status of Epidemiology, Diagnosis, Therapeutics, and Vaccines for Novel Coronavirus Disease 2019 (COVID-19). Journal of microbiology biotechnology. 2020;30(3):313-24.

53. Chu CM, Cheng VC, Hung IF, Wong MM, Chan KH, Chan KS, et al. Role of lopinavir/ritonavir in the treatment of SARS: initial virological and clinical findings. Thorax. 2004;59(3):252-6. 
54. Sheahan TA-O, Sims AA-O, Graham RA-O, Menachery VD, Gralinski LA-O, Case JB, et al. Broadspectrum antiviral GS-5734 inhibits both epidemic and zoonotic coronaviruses. LID 10.1126/scitranslmed.aal3653 [doi] LID - eaal3653. 2017(1946-6242 (Electronic)).

55. Holshue ML, DeBolt C, Lindquist S, Lofy KH, Wiesman J, Bruce H, et al. First Case of 2019 Novel Coronavirus in the United States. N Engl J Med. 2020;382(10):929-36.

56. Mulangu S, Dodd LE, Davey RT Jr, Mbaya T, Proschan O, Mukadi M. D, et al. A Randomized, Controlled Trial of Ebola Virus Disease Therapeutics. N Engl J Med. 2019;381(24):2293-303.

57. Zhang W, Zhao Y, Zhang F, Wang Q, Li T, Liu Z, et al. The use of anti-inflammatory drugs in the treatment of people with severe coronavirus disease 2019 (COVID-19): The Perspectives of clinical immunologists from China. 2020(1521-7035 (Electronic)).

\section{Figures}

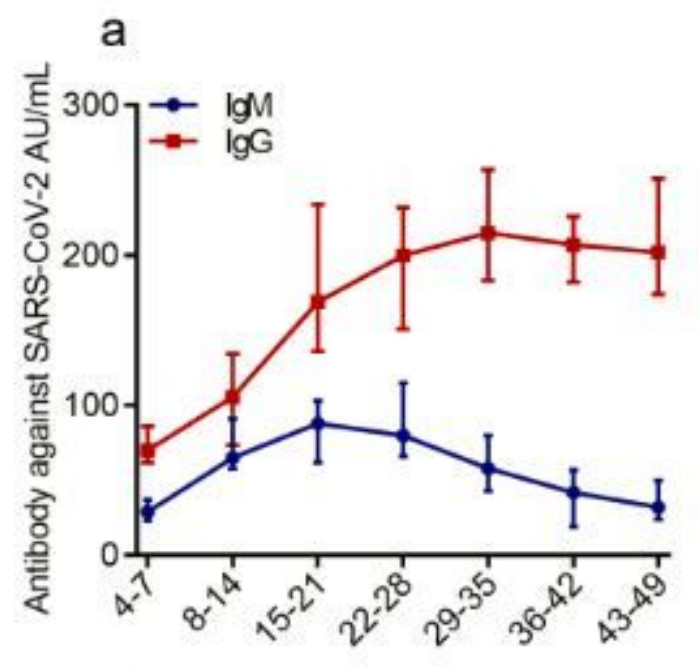

C

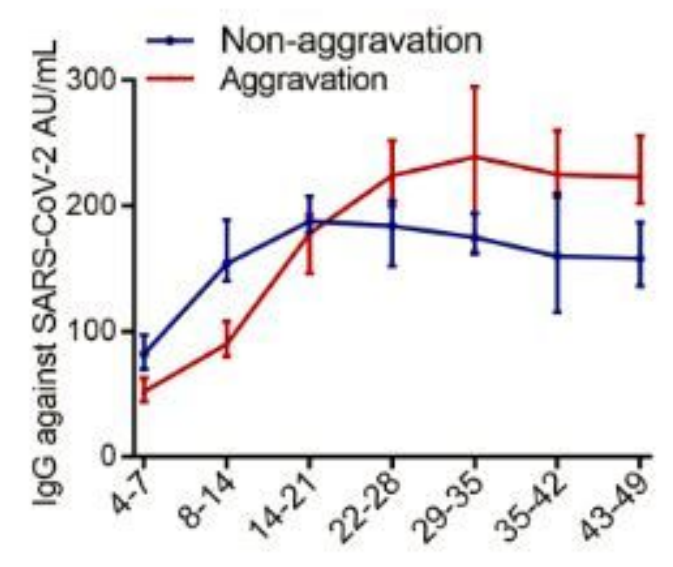

b

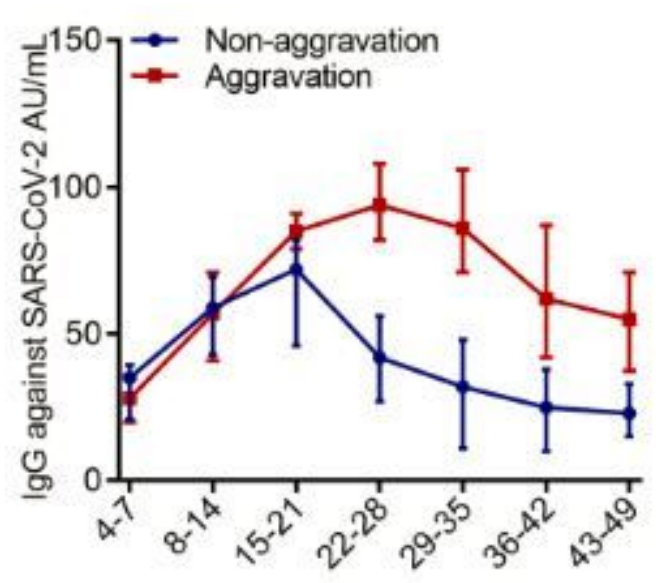

d

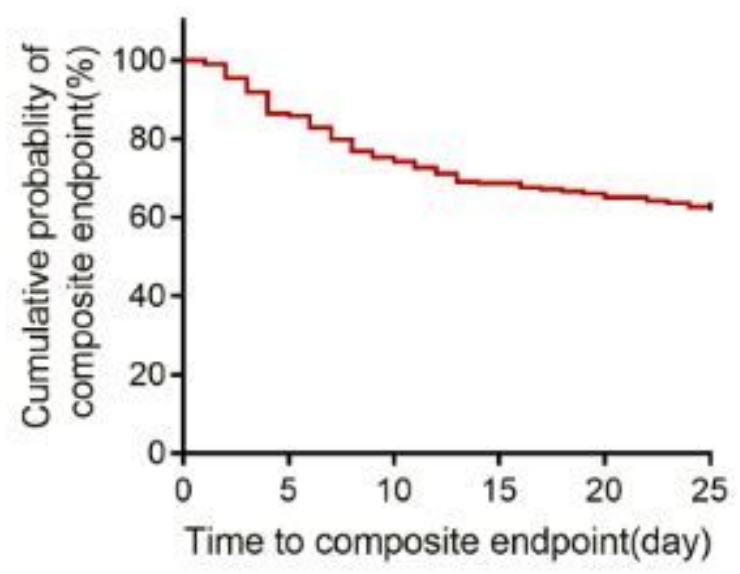

Figure 1 
Dynamics changes of anti-SARS-CoV-2 IgG and IgM in aggravation and non-aggregation groups. (a) The dynamic characteristics of IgM-IgG antibody levels. (b, c) IgM-lgG antibody levels in patients with disease progression and non-progression. (d) Evaluating the prognosis of COVID-19 patients with Kaplan-Meier analysis. The composite endpoint (event) was ICU transfer or death within 25 days from the date of admission to the hospital. The cumulative event-free survival curve was plotted. 